\title{
The Current Situation of Occupational Stress of Special Education Teachers in Jilin Province and Its Relationship with Social Support*
}

\author{
Wei Ji \\ Jilin Agricultural University \\ Changchun, China 130118
}

\author{
Qingfu Xie \\ Jilin Agricultural University \\ Changchun, China 130118
}

\author{
Ying Li \\ Jilin Agricultural University \\ Changchun, Chin 130118
}

\begin{abstract}
To understand the present situation and relationship of occupational stress and coping style of special education teachers in Jilin province. Methods: A total of 120 teachers in four special education schools in Jilin Province were investigated by self - made special education teacher's occupational stress and coping style questionnaire. Results: The occupational stress of special education teachers was more serious and the overall social support was better. There was a significant negative correlation between the dimensions of occupational stress and the total score of social support. Social support was able to predict the special education Teacher's professional pressure. Conclusion: The professional pressure of special education teachers in Jilin Province comes from different aspects, and there are common pressures and different support methods.
\end{abstract}

Keywords-special education teachers; occupational stress; coping style

\section{INTRODUCTION}

It proposes in the Professional Standard for Special Education Teachers (for Trial Implementation), "Special education teachers refer to professionals who educate disabled students in school of special education, regular primary and middle schools and kindergartens as well as institutions, attend strict training to have good professional ethics and grasp systematic professional knowledge and skills". The development of special education requires common efforts of the society, especially special education teachers, the mental health of whom directly influences healthy growth of students. Researches indicate the mental health of teachers and students closely relates. [1-2] Mental health of special education teachers is an important reflection and indicator of teachers' psychological quality, greatly influencing children with special needs and their physical and mental development. Researches have indicated one of the important factors that influence teachers' mental health is occupational stress. [3] It has great

*2016 key planning project of Jilin province educational science in " 13 th Five-year" Plan, project approval No. ZD16043 effect on teachers' improvement, the growth of children with special needs and the development of special education through discussing and paying attention to occupational stress of special education teachers and promoting their mental health. [4] In recent years, teachers' occupational stress has attracted increasing attentions from researchers at home and abroad. Occupational stress often leads to job burnout, depression, absenteeism and outflow of teachers. [5] However, the present researches on teachers' occupational stress research occupational stress of teachers in regular schools instead of special education teachers. The discussions are as follows: how about the occupational stress of special education teachers in Jilin province and the current situation of social support? How about the relationship between occupational stress and social support? How social support influences occupational stress?

\section{RESEARCH METHODS}

\section{A. Research Objects}

120 special education teachers from four schools for special education in Jilin province are selected randomly as research objects. 120 questionnaires are distributed, with 112 valid questionnaires that involve 28 male teachers and 84 female teachers with proportions of 25 percent and 75 percent respectively; 76 young teachers and 36 middle and old aged teachers with proportions of 67.9 percent and 32.1 percent respectively; 15 teachers with advanced degree and 97 teachers with bachelor degree or below with proportions of 13.4 percent and 86.6 percent respectively.

\section{B. Research Tools}

1) Questionnaires of occupational stress for special education teachers

Revise "Questionnaire of Occupational Stress for Primary and Middle School Teachers" compiled by Zhu Congshu, Shen Jiliang and Liu Jiaxia [6], delete individual items unsuitable for special education teachers and amend individual items of 
questionnaire through discussion with experts to make it applicable to special education teachers. The revised questionnaire consists of 45 items. According to the data collected in the research and the analysis on exploratory factors, the questionnaire is divided into six dimensions including students' life, student factor, self-development needs, family relationships, and workload and job expectancy respectively. The fit indexes of analysis on confirmatory factors in the questionnaire are $\chi 2=91.024(\mathrm{df}=24 \mathrm{p}=0.000) ; \quad \mathrm{CFI}=0.901$; TLI $=0.911$; RMSEA $=0.077$. The good goodness of fit indicates the data support model conception. The coefficients of internal consistency of the questionnaire are $0.6472,0.510,0.8403$, $0.7898,0.8452$ and 0.9011 respectively. Likert scale is adopted to score through five aspects (no pressure, a little pressure, general, big pressure and great pressure). The higher the score, the greater pressure the subjects have.

\section{2) Coping style scale}

The "coping style scale" compiled by Xiao Jihua is adopted [7] It is compiled according to the questionnaire of coping research at home and abroad and theories related to "coping" and the cultural background of our country. The scale includes 62 items and six sub-scales including solving problems, selfaccusation, seeking help, fantasy, retreat and rationalization. The correlation coefficients of six coping factors retested are $0.72,0.62,0.69,0.72,0.67$ and 0.72 respectively. The values of factor load in each item are 0.35 or above. Reliability and validity of scale are good. Each item has two answers: "Yes" and "No". If "Yes" is selected, please evaluate the subsequent "valid", "comparatively valid" and "invalid"; if "No" is selected, please continue the next item.

\section{Data Statistics and Processing}

Carry out descriptive statistics, $\mathrm{T}$ check, correlation analysis and regression analysis for the research results according to Spss22.0 statistical package and use AMOS to analyze confirmatory factors in the questionnaire.

\section{RESUlts AND ANALYSIS}

\section{A. Current Occupational Stress of Special Education Teachers}

The revised questionnaire of occupational stress for special education teachers scores at five levels. The scoring of medium level is three. According to the occupational stress and mean value of five factors in "Table I", the mean value of teachers' occupational stress is 2.79 , close to medium level. The mean value of job expectancy is 3.64 and the highest, exceeding medium level. The mean values of workload and selfdevelopment needs are 2.95 and 2.84 respectively, basically reaching the medium level. The mean value of student factor is 2.70 , close to medium value. The mean value of family relationships is 2.15 , which is relatively low.
TABLE I. TEACHERS' OCCUPATIONAL STRESS AND DESCRIPTIVE STATISTICS OF FIVE FACTORS $(\mathrm{N}=120)$

\begin{tabular}{|c|c|c|c|c|}
\hline & $\begin{array}{c}\text { Minimum } \\
\text { value }\end{array}$ & $\begin{array}{c}\text { Maximum } \\
\text { value }\end{array}$ & $\begin{array}{l}\text { Mean } \\
\text { value }\end{array}$ & $\begin{array}{l}\text { Standard } \\
\text { deviation }\end{array}$ \\
\hline Students' life pressure & 1.00 & 4.89 & 2.4402 & 1.15364 \\
\hline Student factor & 1.00 & 4.31 & 2.7038 & .93020 \\
\hline Self-development & 1.00 & 4.33 & 2.8432 & .93309 \\
\hline Family relationships & 1.00 & 5.00 & 2.1538 & 1.20133 \\
\hline Workload & 1.00 & 5.00 & 2.9538 & 1.14797 \\
\hline Job expectancy & 1.00 & 5.00 & 3.6442 & 1.14227 \\
\hline
\end{tabular}

B. Variation Analysis of Special Education Teachers' Occupational Stress and Social Support on Demographic Variable

1) Variation analysis of special education teachers' occupational stress on demographic variables

Carry out $\mathrm{T}$ check for special education teachers' occupational stress on variables of gender, different categories and education background "Table II".

TABLE II. T CHECK OF SPECIAL EDUCATION TEACHERS OCCUPATIONAL STRESS ON DEMOGRAPHIC VARIABLES

\begin{tabular}{llll}
\hline & Gender & \multicolumn{1}{c}{$\begin{array}{c}\text { Different } \\
\text { categories }\end{array}$} & $\begin{array}{c}\text { Education } \\
\text { background }\end{array}$ \\
\hline Students' life & -0.641 & -1.162 & -0.822 \\
Student factor & -0.311 & -0.932 & -0.203 \\
Self-development & 0.144 & -0.86 & -1.452 \\
Family relationship & -0.413 & -1.03 & 0.318 \\
Workload & -0.489 & -0.768 & 0.153 \\
Job expectancy & -0.455 & -0.417 & $-2.052 *$ \\
\hline \multicolumn{2}{l}{ a. Note: *: $\mathrm{p}<0.05: * *: \mathrm{p}<0.01 ; * * *: \mathrm{p}<0.001$, the same below }
\end{tabular}

The job expectancy in special education teachers' occupational stress has significant differences on the variable of education background $(\mathrm{t}=-2.052, \mathrm{P}<0.05)$. The mean value (4.33) of special education teachers with advanced degree is higher than that (3.50) of special education teachers with low academic qualification. Other dimensions in occupational stress have no significant differences on demographic variables.

2) Variation analysis of special education teachers' social support on demographic variables

$\mathrm{T}$ check is carried out for variables of gender, different categories and education background on special education teachers' social support to check whether differences exist.

TABLE III. T CHECK ON DEMOGRAPHIC VARIABLES FOR SPECIAL EDUCATION TEACHERS' SOCIAL SUPPORT

\begin{tabular}{llll}
\hline & Gender & $\begin{array}{c}\text { Different } \\
\text { categories }\end{array}$ & $\begin{array}{c}\text { Education } \\
\text { background }\end{array}$ \\
\hline Objective support & -0.75 & 0.508 & 1.295 \\
Subjective support & -1.627 & 0.565 & 1.324 \\
Availability of support & $-3.025^{* *}$ & -0.165 & 0.806 \\
Social support & -5.394 & 4.579 & 2.385
\end{tabular}

The availability of support in special education teachers social support has significant differences on the variable of gender $(\mathrm{t}=-3.025, \mathrm{P}<0.01)$. The mean value $(7.31)$ of male teachers' social support is higher than that of female teachers 
(5.83). Other dimensions of social support on demographic variables have no significant differences "Table III".

\section{Relationship between Occupational Stress and Social Support of Special Education Teachers}

The relationship between special education teachers' occupational stress and social support is analyzed through Pearson product-moment correlation.

TABLE IV. RELATIONSHIP BETWEEN SPECIAL EdUCATION TEACHERS' OCCUPATIONAL StRESS AND SOCIAL SUPPORT

\begin{tabular}{|c|c|c|c|c|c|c|}
\hline & Examination stress & Student factor & Self-development & Family relationship & Workload & Job expectancy \\
\hline Objective support & $-.289^{*}$ & -0.241 & -0.251 & -0.124 & -0.187 & $-.297 *$ \\
\hline Subjective support & 0.206 & 0.211 & 0.207 & 0.154 & $-.240^{*}$ & -0.01 \\
\hline Availability of support & -0.079 & -0.064 & -0.157 & -0.085 & 0.112 & -0.098 \\
\hline Social support & $-.485^{*}$ & $-.642 *$ & $-.461^{*}$ & $.316^{*}$ & $-.164^{*}$ & $-.562 *$ \\
\hline
\end{tabular}

Relationship between special education teachers occupational stress and social support: objective support has significant negative correlation with examination stress and job expectancy; subjective support has significant negative correlation with workload; availability of support has no correlation with dimensions of occupational stress; the total score of social support has significant negative correlation with examination stress, student factor, self-development needs, family relationship, workload and job expectancy "Table IV".

\section{Regression Analysis of Special Education Teachers' Social Support on Occupational Stress}

In order to research the predictive effects of gender, teachers' category, education background and social support on special education teachers' occupational stress, take dimensions of occupational stress as dependent variables, take demographic variables (gender, teachers' category and education background) as predictive variables at the first level and three dimensions of social support as predictive variables at the second level to carry out multiple linear regression analysis.

1) Regression analysis of gender, teachers' category, education background and social support on students' life pressure in occupational stress

Adopt Forced Enter in the Multiple Linear Regression and bring demographic variables (gender, teachers' category and education background) and three dimensions of social support (objective support, subjective support and availability of support) in the equation to predict students' life pressure in occupational stress.

TABLE V. REgRESSION ANALYSIS OF GENDER, TEACHERS’ CATEGORY, EDUCATION BACKGROUND AND SOCIAL SUPPORT ON STUDENTS’ LiFE PRESSURE IN OCCUPATIONAL STRESS

\begin{tabular}{|c|c|c|c|c|c|c|}
\hline Variation source & $\begin{array}{c}\text { Adjust R } \\
\text { square }\end{array}$ & B & $\begin{array}{c}\text { Standard error of } \\
\text { B }\end{array}$ & $\begin{array}{l}\text { Standard } \\
\text { coefficient }\end{array}$ & $\mathbf{T}$ & Sig. \\
\hline Constant quantity & & 1.289 & 1.130 & & 1.140 & .260 \\
\hline Gender & .182 & .287 & .325 & .124 & .881 & .383 \\
\hline Teachers' category & .112 & .456 & .369 & .163 & 1.237 & .223 \\
\hline Education background & .025 & .127 & .413 & .042 & .307 & .760 \\
\hline Objective support & .420 & -.131 & .045 & -.399 & -2.913 & $.006^{*}$ \\
\hline Subjective support & .533 & .172 & .055 & .476 & 3.104 & $.003 *$ \\
\hline Availability of support & .236 & -.170 & .095 & -.277 & -1.791 & .080 \\
\hline
\end{tabular}

"Table V" shows objective support and subjective support can significantly predict students' life pressure.

2) Regression analysis of gender, teachers' category, education background and social support on student factor in occupational stress

Adopt Forced Enter in the Multiple Linear Regression and bring demographic variables (gender, teachers' category and education background) and three dimensions of social support (objective support, subjective support and availability of support) in the equation to predict examination stress in occupational stress.

TABLE VI. REgRession ANALYSIS OF GENDER, TEACHERS' CATEGORY, EDUCATION BACKGROUND AND SOCIAL SUPPORT ON STUdENT FACTOR IN OCCUPATIONAL STRESS

\begin{tabular}{lllllll}
\hline \multicolumn{1}{c}{ Variation source } & Adjust R square & B & \multicolumn{2}{c}{$\begin{array}{c}\text { Standard error of } \\
\text { B }\end{array}$} & $\begin{array}{c}\text { Standard } \\
\text { coefficient }\end{array}$ & T \\
\hline Constant quantity & & 1.727 & .949 & & 1.820 & .075 \\
Gender & .113 & .142 & .273 & .076 & .521 & .605 \\
Teachers' category & .108 & .342 & .309 & .152 & 1.107 & .274 \\
Education background & .084 & -.073 & .347 & -.030 & -.210 & .834 \\
Objective support & .042 & -.094 & .038 & -.355 & -2.491 & .017 \\
Subjective support & .342 & .130 & .046 & .446 & 2.795 & $.008^{*}$ \\
Availability of support & .158 & -.121 & .079 & -.245 & -1.521 & .135 \\
\hline
\end{tabular}


"Table VI" shows objective support can significantly predict student factor but the regression equation is insignificant.

3) Regression analysis of gender, teachers' category, education background and social support on self-development needs in occupational stress
Adopt Forced Enter in the Multiple Linear Regression and bring demographic variables (gender, teachers' category and education background) and three dimensions of social support (objective support, subjective support and availability of support) in the equation to predict self-development needs in occupational stress.

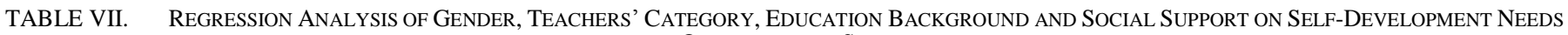
IN OCCUPATIONAL STRESS

\begin{tabular}{|c|c|c|c|c|c|c|}
\hline Variation source & Adjust R square & $\mathbf{B}$ & Standard error of B & Standard coefficient & $\mathbf{T}$ & Sig. \\
\hline Constant quantity & & 1.502 & 1.286 & & 1.168 & .249 \\
\hline Gender & .023 & .289 & .370 & .120 & .780 & .440 \\
\hline Teachers' category & .035 & .547 & .419 & .188 & 1.303 & .199 \\
\hline Education background & .124 & -.366 & .470 & -.116 & -.779 & .440 \\
\hline Objective support & .136 & -.071 & .051 & -.208 & -1.387 & .172 \\
\hline Subjective support & .310 & .121 & .063 & .324 & 1.931 & .060 \\
\hline Availability of support & .116 & -.169 & .108 & -.265 & -1.566 & .124 \\
\hline
\end{tabular}

"Table VII" shows the regression equation is significant; objective support, subjective support and availability of support can significantly predict self-development needs.

4) Regression analysis of gender, teachers' category, education background and social support on family relationships in occupational stress

Adopt Forced Enter in the Multiple Linear Regression and bring demographic variables (gender, teachers' category and education background) and three dimensions of social support (objective support, subjective support and availability of support) in the equation to predict family relationships in occupational stress.

TABLE VIII. REGRESSION ANALYSIS OF GENDER, TEACHERS' CATEGORY, EDUCATION BACKGROUND AND SOCIAL SUPPORT ON FAMILY RELATIONSHIPS IN OCCUPATIONAL STRESS

\begin{tabular}{lllllll}
\hline \multicolumn{1}{c}{ Variation source } & Adjust R square & B & \multicolumn{2}{c}{$\begin{array}{c}\text { Standard error of } \\
\text { B }\end{array}$} & $\begin{array}{c}\text { Standard } \\
\text { coefficient }\end{array}$ & T \\
\hline Constant quantity & & 1.524 & .906 & & & 1.683 \\
Gender & .197 & .002 & .261 & .001 & .099 & .008 \\
Teachers' category & .154 & .228 & .295 & .101 & .772 & .444 \\
Education background & .065 & .424 & .331 & .174 & 1.282 & .206 \\
Objective support & .384 & -.089 & .036 & -.336 & -2.478 & .007 \\
Subjective support & .624 & .153 & .044 & .525 & 3.457 & .001 \\
Availability of support & .452 & -.162 & .076 & -.327 & -2.132 & .009 \\
\hline
\end{tabular}

"Table VIII" shows the regression equation is insignificant; objective support, subjective support and availability of support cannot significantly predict family relationship.

5) Regression analysis of gender, teachers' category, education background and social support on workload of occupational stress

Adopt Forced Enter in the Multiple Linear Regression and bring demographic variables (gender, teachers' category and education background) and three dimensions of social support (objective support, subjective support and availability of support) in the equation to predict workload in occupational stress.

TABLE IX. REgRESSION ANALYSIS OF GENDER, TEACHERS' CATEGORY, EDUCATION BACKGROUND AND SOCIAL SUPPORT ON WORKLOAD OF OCCUPATIONAL STRESS

\begin{tabular}{|c|c|c|c|c|c|c|}
\hline Variation source & $\begin{array}{c}\text { Adjust R } \\
\text { square }\end{array}$ & $\overline{\mathbf{B}}$ & Standard error of B & $\begin{array}{l}\text { Standard } \\
\text { coefficient }\end{array}$ & $\bar{T}$ & Sig. \\
\hline Constant quantity & & 1.605 & 1.214 & & 1.322 & .193 \\
\hline Gender & .047 & .073 & .349 & .032 & .210 & .835 \\
\hline Teachers' category & .032 & .353 & .396 & .127 & .891 & .378 \\
\hline Education background & .028 & -.156 & .444 & -.052 & -.352 & .726 \\
\hline Objective support & .341 & -.103 & .048 & -.314 & -2.126 & $.039 *$ \\
\hline Subjective support & .522 & .127 & .059 & .355 & 2.147 & $.037 *$ \\
\hline Availability of support & .240 & -.011 & .102 & -.018 & -.110 & .913 \\
\hline
\end{tabular}

"Table IX" shows the regression equation is insignificant, but objective support and subjective support can significantly predict workload.

6) Regression analysis of gender, teachers' category, education background and social support on job expectancy of occupational stress

Adopt Forced Enter in the Multiple Linear Regression and bring demographic variables (gender, teachers' category and education background) and three dimensions of social support (objective support, subjective support and availability of support) in the equation to predict job expectancy in occupational stress. 
TABLE X. REgRESSION ANALySIS OF GENDER, TEACHERS' CATEGORY, EDUCATION BACKGROUND AND SOCIAL SUPPORT ON JOB EXPECTANCY OF OCCUPATIONAL STRESS

\begin{tabular}{|c|c|c|c|c|c|c|}
\hline Variation source & Adjust R square & $\bar{B}$ & Standard error of B & Standard coefficient & $\mathbf{T}$ & Sig. \\
\hline Constant quantity & & 3.306 & 1.198 & & 2.759 & .008 \\
\hline Gender & .062 & .172 & .345 & .075 & .499 & .620 \\
\hline Teachers' category & .156 & -.026 & .391 & -.009 & -.065 & .948 \\
\hline Education background & .120 & .708 & .438 & .237 & 1.617 & .113 \\
\hline Objective support & .421 & -.099 & .048 & -.305 & -2.081 & $.043 *$ \\
\hline Subjective support & .201 & .067 & .059 & .189 & 1.152 & .256 \\
\hline Availability of support & .046 & -.079 & .100 & -.130 & -.787 & .435 \\
\hline
\end{tabular}

"Table X" shows the regression equation is insignificant, but objective support can significantly predict job expectancy.

\section{DISCUSSION}

\section{A. Current Situation of Special Education Teachers Occupational Stress}

Table 1 indicates special education teachers have serious problems in occupation stress which has been nearly medium level. The pressure in job expectancy is the greatest (3.64), reaching above medium level. According to the interview of special education teachers, they have pressures because they feel their social status is low and the payment is fewer than their dedication. It shows insufficient attentions are paid to special education teachers. Other pressures come from workload, self-development and student factor, which reach nearly medium level, but family relationships bring less pressure. The researches on teachers' occupational stress at home and abroad indicate teachers' occupational stress is ubiquitous. In 1976, the questionnaire survey carried out by J.Dunham indicated most teachers suffered from stress at different levels. [8] According to the investigation of $\mathrm{Xu}$ Changjiang on teachers in three middle schools of Heilongjiang province, 52.1 percent of teachers think their occupational stress is very great or extremely great. [9] $\mathrm{Xu}$ Fuming's research shows 67.4 percent of primary and middleschool teachers think they face great or very great work stress. [10]

\section{B. Variation Analysis of Special Education Teachers' Occupational Stress and Social Support on Demographic Variables}

Table 2 and table 3 indicate special education teachers' job expectancy has significant differences on education background ( $\mathrm{t}=-2.052, \mathrm{P}<0.05$ ). The mean value (4.33) of job expectancy of special education teachers with advanced degrees is higher than that (3.50) with low academic qualification. Special education teachers with advanced degrees have more pursuit of job expectancy. Traditional social factors show the higher the education background, the greater the achievements will be. Special education teachers with advanced degrees have greater job expectancy. Other dimensions of occupational stress have no significant differences on demographic variables. With social development, attentions paid to special education and policy tendency, the differences of demographic variables such as education background and different categories on occupational stress gradually decrease. Special education teachers' availability of support on gender has significant differences $(\mathrm{t}=-3.025, \mathrm{P}<0.01)$. The mean value of male teachers' social support (7.31) is higher than that of female teachers (5.83), which indicate male teachers have better performance on availability of social support than female teachers. It may be because male teachers can better make use of resources. Moreover, male teachers spend more time in dealing with things beyond the family and have more social interaction than female teachers, so they can better make use of social supports.

\section{Discussion on Relationship of Special Education Teachers' Occupational Stress and Social Support}

Table 4 indicates the total score of special education teachers' social support has significant negative correlation with occupational stress. That is to say, the higher the social support, the less the occupational stress of special education teachers will be. It conforms to the previous results in researches on primary and middle school teachers. Yu Jing tests 180 teachers in four middle schools and the results indicate occupational stress and social support have significant correlation. [11]Gao Ping and Zhang Ning investigate 468 primary and middle school teachers and draw the conclusion that teachers' occupational stress and social support have significant correlation. [12] Objective support has significant negative correlation with examination stress and job expectancy, which indicate that external factors have good effect on reducing special education teachers' examination stress and job expectancy. Subjective support has significant negative correlation with workload, which indicates the decrease of work stress depends on teachers instead of external factors and support from friends.

\section{Discussion on Regression Analysis of Special Education Teachers' Social Support on Occupational Stress}

The research discusses the prediction of special education teachers' occupational stress through gender, teachers' category, education background and social support. Tables 5 to 10 indicate social support can predict teachers' occupational stress. Objective support predicts special education teachers' examination stress, student factor, self-development needs and workload and job expectancy very well. Objective support is objective, visible or practical, including direct material assistance and the existence and participation of social network and group relation. These supports are independent from feelings of individuals, referring to the reality with objective existence. It shows objective factors can relieve special education teachers' stress. Subjective support can predict special education teachers' examination stress, selfdevelopment needs and job expectancy. Neither subjective 
support nor objective support can predict the stress from family relationships. Subjective support is subjective or emotional support, referring to the emotional experience and satisfaction degree that individuals are respected, supported and understood in society, closely relating to individuals' subjective feeling. [13] It indicates subjective factors have important effects on decreasing special education teachers' examination stress, self-development needs and job expectancy.

\section{CONCLUSION}

- Special education teachers in Jilin province have great occupational stress which reaches medium and above level; special education teachers have good performance in utilizing social support.

- Special education teachers' occupational stress has significant differences on education background; social support has significant differences on gender and no significant differences on other variables.

- Special education teachers' occupational stress has significant negative correlation with the total score of social support.

- Social support can predict special education teachers' occupational stress well.

\section{REFERENCES}

[1] Zhu Mei, Dong Liping, Du Ruihong. Influence of Teachers' Job Burnout and Mental Health Status on Mental Health of Primary and Secondary School Students [J], Chinese Journal of School Health, 2010, 31(7): 802-803

[2] Xie Aiwu. Mental Health Status of Middle School Teachers and Its Relationship with Students' Mental Health Status [J], China Journal of Health Psychology, 2003, 11(3): 217-219

[3] Wang Wenzeng, Guo Liyan. Occupational Stress, Job Burnout and Mental Health of Primary and Middle School Teachers [J], Chinese Journal of Clinical Psychology, 2007, 15(2): 146-148

[4] He Wenjun. Research Review on Mental Health of Domestic Special Education Teachers [J], Journal of Suihua University, 2013, 33(4): 3134

[5] Wang Lingfeng. Investigation and Analysis on Occupational Stress of Special Education Teachers [J], Chinese Journal of Special Education, 2009(8): 57-60

[6] Yang Liu, Meng Wanjin. Social Support of Special Education Teachers [J], Chinese Journal of Special Education, 2013(3): 20-23+30

[7] Cao Hui, Xiao Wei, Cao Pin. College Students' Social Anxiety and Its Relationship with Coping Style [J], Journal of Beijing University of Posts and Telecommunications (Social Science Edition), 2008, 10(4): $75-80$

[8] Zhu Congshu, Shen Jiliang. Source of Occupational Stress of Primary and Middle School Teachers [J], Modern Primary and Secondary Education, 2002(3): 50-54

[9] Xiao Jihua, Xu Xiufeng. Validity and Reliability of "Coping Style Questionnaire" [J], Chinese Mental Health Journal, 1996(4): 164-168

[10] Cher I J Travers \& Cary L Cooper. Teachers Under Pressure: Stress in the Teaching Profession[M]. Routledge, london and New York, 19960

[11] Xu Changjiang. Investigation on Occupational Stress of Middle School Teachers and Its Reasons [J], Journal of Zhejiang Normal University (Social Science Edition), 1998, 6
[12] Xu Fuming. Current Situation of Work Stress of Primary and Middle School Teachers and Its Relationship with Job Burnout [J], Chinese Journal of Clinical Psychology, 2003, 11(3)

[13] Yu Jing. Research on Middle School Teachers' Mental Health and Occupational Stress and Social Support [J], Modern Primary and Secondary Education, 2005(11): 50-52

[14] Gao Ping, Zhang Ning. Relationships Among Occupational Stress of Primary and Middle School Teachers, Social Support and Teaching Efficacy [J], China Journal of Health Psychology, 2009, 17(6): 680-682

[15] Xiao Shuiyuan. Theoretical Basis of Social Support Revalued Scale and Research and Application, Journal of Clinical Psychiatry, 1994, 4(2) 